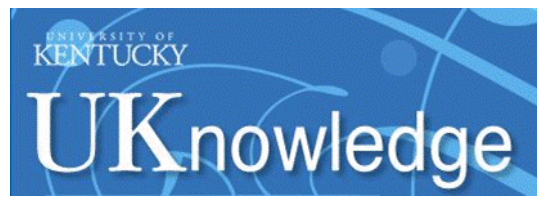

University of Kentucky

UKnowledge

Biosystems and Agricultural Engineering Faculty Publications

\title{
Enzymatic Hydrolysis of Biomass at High-Solids Loadings - A Review
}

\author{
Alicia A. Modenbach \\ University of Kentucky, alicia.modenbach@uky.edu \\ Sue E. Nokes \\ University of Kentucky, sue.nokes@uky.edu
}

Follow this and additional works at: https://uknowledge.uky.edu/bae_facpub

Part of the Bioresource and Agricultural Engineering Commons, and the Enzymes and Coenzymes

Commons

Right click to open a feedback form in a new tab to let us know how this document benefits you.

\section{Repository Citation}

Modenbach, Alicia A. and Nokes, Sue E., "Enzymatic Hydrolysis of Biomass at High-Solids Loadings - A Review" (2013). Biosystems and Agricultural Engineering Faculty Publications. 168.

https://uknowledge.uky.edu/bae_facpub/168

This Review is brought to you for free and open access by the Biosystems and Agricultural Engineering at UKnowledge. It has been accepted for inclusion in Biosystems and Agricultural Engineering Faculty Publications by an authorized administrator of UKnowledge. For more information, please contact UKnowledge@lsv.uky.edu. 


\section{Enzymatic Hydrolysis of Biomass at High-Solids Loadings - A Review}

\section{Digital Object Identifier (DOI)}

https://doi.org/10.1016/j.biombioe.2013.05.031

\section{Notes/Citation Information}

Published in Biomass and Bioenergy, v. 56, p. 526-544.

(C) 2013. This manuscript version is made available under the CC-BY-NC-ND 4.0 license https://creativecommons.org/licenses/by-nc-nd/4.0/

The document available for download is the authors' post-peer-review final draft of the article 
1 Enzymatic hydrolysis of biomass at high-solids loadings - A review

2

3 Alicia A. Modenbach ${ }^{\mathrm{a}}$, Sue E. Nokes ${ }^{\mathrm{a}}$

4

5 a Department of Biosystems and Agricultural Engineering, University of Kentucky, Lexington, 6 Kentucky, United States 40546

7

8 Corresponding Author: Alicia A. Modenbach

9 Phone: (859) 257-3000

10 Email: alicia.modenbach@uky.edu

11 Address: 128 CE Barnhart Building, University of Kentucky, Lexington, KY 40546

12 Fax: (859) 257-5671 


\section{Abstract}

14 Enzymatic hydrolysis is the unit operation in the lignocellulose conversion process that

15 utilizes enzymes to depolymerize lignocellulosic biomass. The saccharide components released

16 are the feedstock for fermentation. When performed at high-solids loadings ( $\geq 15 \%$ solids, w/w),

17 enzymatic hydrolysis potentially offers many advantages over conversions performed at low- or

18 moderate-solids loadings, including increased sugar and ethanol concentrations and decreased

19 capital and operating costs.

20 The goal of this review is to provide a consolidated source of information on studies

21 using high-solids loadings in enzymatic hydrolysis. Included in this review is a brief discussion

22 of the limitations, such as a lack of available water, difficulty with mixing and handling,

23 insufficient mass and heat transfer, and increased concentration of inhibitors, associated with the

24 use of high solids, as well as descriptions and findings of studies that performed enzymatic

25 hydrolysis at high-solids loadings. Reactors designed and/or equipped for improved handling of

26 high-solids slurries are also discussed. Lastly, this review includes a brief discussion of some of

27 the operations that have successfully scaled-up and implemented high-solids enzymatic

28 hydrolysis at pilot- and demonstration-scale facilities.

30 Keywords: High-solids loadings; enzymatic hydrolysis; lignocellulose conversion; reactor

31 design; corn stover; straw; woody biomass 


\section{Introduction}

Lignocellulose is the largest renewable source of carbon on the planet, as it is the main

34 structural component of plants. Energy from lignocellulosic biomass has been tapped as one

35 possible solution to decrease the United States' foreign dependence on petroleum, as well as

36 serve as a more environmentally friendly source of energy. Lignocellulose can either be

37 processed thermochemically or biochemically, depending on the desired product. The

38 biorefinery concept is thought to be the desired model for biomass processing, where all of the

39 biomass is exploited. The suite of products would be dictated by the market and selected to

40 extract the greatest value possible out of lignocellulose (Figure 1).

41 Enzymatic hydrolysis of lignocellulose has long been studied as a method to

42 depolymerize the biomass into fermentable sugars for conversion to biofuels and biochemicals,

43 with a more recent focus on operating at high-solids loadings. It has been suggested that

44 enzymatic hydrolysis conducted at high-solids loadings will be necessary to render the

45 lignocellulosic conversion process more economically feasible. A process is considered "high

46 solids" if the ratio of solids/liquid is such that very little to no free water is present in the slurry

47 [1] or roughly a solids loadings $\geq 15 \%$ (w/w).

Enzymatic hydrolysis performed at high-solids loadings offers several advantages over

49 low- and moderate-solids loadings, the main one being final sugar concentrations are higher [2,

$503]$. In theory, higher sugar concentrations translate into higher ethanol concentrations, which

51 could reduce energy use and costs associated with the distillation process $[4,5]$. For the purpose

52 of this paper, the term "concentration" refers to the amount of a component dissolved in a given

53 volume of liquid, while the terms "yield" and "conversion" refer to the quantity of a product

54 obtained expressed as a percentage of the theoretical maximum. Distillation is most economical 
55 when the ethanol concentration is $\geq 4 \%$ (w/w). In order to obtain this ethanol yield, glucose

56 yields must be at least $8 \%(\mathrm{w} / \mathrm{w})$, which translated into a lignocellulose loading of $\geq 20 \%(\mathrm{w} / \mathrm{w})$

57 for enzymatic hydrolysis [6]. These estimates only account for conversion of cellulose;

58 however, as improvements are made to hemicellulose conversion (hydrolysis and fermentation)

59 technologies that work in combination with cellulose conversion, this initial solids loadings

60 estimate may decrease. Another potential advantage is the reduction of capital and production

61 costs. Smaller equipment and/or fewer reactors can be utilized to produce an equivalent output

$62[7,8]$. Fewer reactors also translate into reduced energy demands for heating, cooling and

63 mixing $[3,5]$, although the latter aspect may be a point of contention as increased solids makes

64 effective mixing more difficult. Additionally, less water is needed, which reduces the cost of

65 disposal or treatment of process water.

66 The goal for this review is to provide a consolidated source of information for the latest

67 technological advances for managing enzymatic hydrolysis at high-solids loadings. Following a

68 brief discussion of the factors limiting enzymatic hydrolysis at high solids, various aspects and

69 approaches pertaining to hydrolysis operating conditions are detailed. Additionally, reactors

70 designed to overcome some of the limitations associated with high-solids hydrolysis, as well as

71 pilot- and demonstration-scale plants operating at high-solids loadings are discussed. Lastly, the

72 authors comment on the envisioned direction for high-solids hydrolysis research, as well as the

73 necessary advances this technology must make to become commercially viable.

\section{2. Factors Limiting High-Solids Enzymatic Hydrolysis}

As solids loading increases, challenges that were negligible in low-solid systems become

77 more prominent, which has also been noted in high solids pretreatment [9]. One of the major 
challenges for enzymatic hydrolysis at high solids loading is the lack of available water in the

79 reactor. Water is essential to effective hydrolysis for two reasons: mass transfer and lubricity.

80 Water increases the effectiveness of the enzymatic and chemical reactions, mainly by providing a

81 medium for solubilizing and aiding in the mass transfer of products. Water also reduces the

82 viscosity of the slurry by increasing the lubricity of the particles, which decreases the required

83 shear stress necessary to produce a given shear rate, allowing lower power input for mixing [1,

84 10]. The physical and chemical properties of the specific biomass affect the way biomass

85 absorbs water. As solids loadings approach 20\% (w/w), the liquid fraction becomes fully

86 absorbed into the biomass leaving little free water [1]. With lower amounts of free water, the

87 apparent viscosity of the mixture increases, and consequently mixing and handling of material

88 become more difficult.

89 Gervais, Benoussan and Grajek [11] investigated the relationship between water content

90 and water activity on microorganisms in a high-solids cellulose environment. No free water

91 occurs when the matric potential of the substrate holds the water more tightly within its pores

92 than the gravitational force acts on it. The water potential $(=$ osmotic potential + matric

93 potential) of the system is such that content affects mass transfer by limiting diffusion of

94 products away from enzyme [11]. Not only can the enzymes release compounds from the

95 biomass that are inhibitory to the organisms used in the fermentation step, but the sugar products

96 they produce are known inhibitors in the enzymatic feedback mechanism $[2,12,13]$. For

97 example, cellobiose inhibits the cellulase. Typically, cellulase is supplemented with $\beta$ -

98 glucosidase to reduce the inhibition by cellobiose. However, it has recently been shown that

99 hydrolysis rates of cellulase and $\beta$-glucosidase are greatly impacted by hemicellulose-derived

100 products, like xylose, xylan and xylo-oligomers [14-16]. Pretreatment methods that do not 
101 remove these products or enzyme cocktails that include xylanases may have detrimental effects

102 on glucose yields. While inhibition occurs at low solids, as well as at high solids, the increased

103 concentration of inhibitors, in addition to the reduced mass transfer rate away from the enzyme,

104 makes inhibition more apparent at high-solids loadings.

105 The challenges apparent at high solids are interrelated, so a less-than-ideal condition in

106 one property exacerbates the negative effects of another property. For example, the substrates'

107 physio/chemical properties affect the water retention value (WRV) of the biomass. A high WRV

108 (due to high-solids content and the specific properties of the substrate) reduces the diffusion of

109 inhibitors away from the enzymatic reaction, and increases the apparent viscosity of the mixture,

110 thereby increasing the difficulty of stirring the mixture to assist with diffusion. Zhang et al. [17]

111 found that the energy required to mix increased one order of magnitude when they increased the

112 solids loading of pretreated corn stover from $15 \%$ to $30 \% \mathrm{w} / \mathrm{w}(79.5 \mathrm{MJ} / \mathrm{t}$ slurry to $1009.2 \mathrm{MJ} / \mathrm{t}$

113 slurry, respectively) to produce 854.9 and $1723.2 \mathrm{MJ} / \mathrm{t}$ slurry of ethanol respectively. The higher

114 solids loading did indeed achieve the goal of producing a higher concentration of ethanol in the

115 broth; however, over half of the energy produced in the ethanol was consumed in the mixing to

116 achieve the higher concentration of ethanol (compared to $9 \%$ of the energy needed to mix the

117 system producing the lower concentration of ethanol.

118 While it is widely recognized that increasing the solids content in a conversion process

119 increases product concentration [18], it is also widely recognized that the increase in yield is not

120 linear with increasing initial solids content because yield (percent conversion) decreases with

121 initial solids content (slope is a function of substrate type, pretreatment, and enzyme loading,

122 among other things) [10]. In fact, this well-recognized challenge was observed so often that

123 Kristensen et al. [10] coined the term solids effect to describe the persistence of a measured 
124 reduction in conversion when solids loadings are increased. The scientific community has yet to

125 come to agreement as to the cause of the solids effect; however, theories include substrate

126 effects, product inhibition, water content and enzyme adsorption characteristics, just to name a

127 few [10].

128 Other challenges specific to high-solids enzymatic hydrolysis include long hydrolysis

129 times. Enzymatic hydrolysis is typically thought to be the bottleneck of the entire conversion

130 process in terms of both time and money, since the reaction time needed for most enzymes to

131 convert lignocellulose into sufficient glucose concentrations for fermentation is on the order of

132 days (usually $\geq 3$ days). Long hydrolysis times can only be reduced so much by increasing

133 enzyme loading. Recent studies have suggested that enzymes can overcrowd accessible

134 cellulose sites, thus not reaching the full hydrolytic potential for the given enzyme loading [19,

135 20]. Adjacent cellulose chains are 4-6 $\AA$ apart, whereas the diameter of the cellulases is about

136 10-fold larger at about $45 \AA$ (Figure 2). Furthermore, as in low-solids hydrolysis, the cost of the

137 enzyme is also a limiting factor. Enzyme is typically added on a per weight of substrate basis.

138 As the solids loading increases so must the amount of enzyme. While the cost of enzymes has

139 decreased drastically over the years due to intense research developing cheaper production

140 schemes, the cost is still at a level that makes this step in the conversion process one of the most

141 expensive. Finding or developing enzymes with a high activity and inexpensive method of

142 production would greatly benefit the entire conversion process. Moreover, it is also important to

143 evaluate the economics when determining the balance between the loadings applied to the

144 lignocellulose and the amount of time needed to reach sufficient glucose concentrations. 


\section{Impacting Rheology of High-Solids Mixtures}

Rheology is the branch of physics that deals with the deformation and flow of matter. At

148 higher lignocellulose loadings, fundamental understanding of the rheology of these suspensions

149 becomes a powerful tool in designing conversion equipment and processes [21-24]. Factors

150 which contribute to the rheological properties of a suspension include particle size distribution,

151 particle aspect ratio, fiber flexibility $[22,25]$ and physio/chemical properties of the substrate.

152 Water retention value (WRV) of the substrate directly impacts the apparent viscosity of a

153 suspension, affecting mixing and handling of the slurries [26]. For example, pretreated corn

154 stover (PCS) slurries are considered "pourable" when yield stresses are at or below $10 \mathrm{~Pa}$ or

$155 \sim 10 \%$ insoluble solids [3, 23]. Dilute acid PCS at 20\% insoluble solids is a thick, paste-like

156 substance that can be molded and formed into shapes that remain even after the applied forces

157 are removed [23]. At even higher solids loadings ( $>30 \%)$, particles are not as lubricated because

158 of the lack of free water, resulting in increased friction due to particles interacting with both

159 water and other particles. At this point, the mixture can no longer be called a slurry because it is

160 unsaturated and acts more like a wet, granular substance. Substances with these varied

161 rheological properties present many unique challenges in materials handling throughout a

162 conversion process, particularly when continuous, industrial-scale processes are desired.

163 Several rheological models of interest, like the Bingham, Herschel-Buckley, Power Law,

164 Wildemuth-Williams and Casson models [3, 8, 21, 24, 27], have been developed to describe the

165 non-Newtonian behavior of these types of systems, but discussion of these models is beyond the

166 scope of this paper.

167 Um and Hanley [8] analyzed rheological properties of high-solids (10-20\% w/v)

168 enzymatically hydrolyzed slurries of the model cellulose feedstock Solka Floc, a delignified 
169 spruce pulp. Commercially-available Trichoderma longibrachiatum-sourced enzymes (30

170 FPU/g cellulose supplemented with $\beta$-glucosidase) were evaluated at 10,15 and $20 \%$ solids

171 loadings. The enzymatic suspensions exhibited a pseudoplastic behavior overall, with viscosities

172 ranging from 0.04 to $0.01,0.23$ to 0.03 , and 0.29 to $0.04 \mathrm{~Pa} \cdot \mathrm{s}$ for substrate concentrations of 10 ,

17315 and $20 \%$ (respectively) initial solids measured at $50{ }^{\circ} \mathrm{C}$. As the hydrolysis progressed, a

174 decrease in viscosity was observed for all solids loadings (dropping by approximately half in 3

175 hours). Zhang et al. [18] showed the same trend with high-solids steam exploded corn stover.

176 Several studies using dilute acid-pretreated corn stover also observed a reduction in yield stress

177 (and therefore viscosity) as solids loadings in enzymatic hydrolysis decreased (Figure 3) [3, 21,

$17822,24,27]$.

179 Additionally, Roche et al. [3] found that at $20 \%$ solids, $>40 \%$ conversion was necessary

180 for the slurry to become pourable. They also reported a distinct difference between PCS that was

181 enzymatically hydrolyzed as compared to PCS that was just diluted. The yield stress for diluted

182 PCS is higher by a full order of magnitude than that of hydrolyzed PCS at corresponding particle

183 volume fractions. Although specific mechanisms for this difference were not investigated, one

184 theory is that the enzymes alter the particles during hydrolysis, converting them from complex

185 networks of material with distinct liquid and solid phases, to a homogeneous slurry as the liquid

186 and solid phases become indistinguishable.

187 Particle size affects the rheological properties of the suspensions, directly impacting

188 mixing and pumping costs [27]. Viamajala et al. [24] found that smaller particle sizes resulted in

189 smaller apparent viscosities under equivalent conditions. Mechanical pretreatment is often

190 utilized to reduce particle size to make the rheological properties more favorable for other steps

191 downstream in the process. However, temperature and acid concentration in dilute acid 
192 pretreatment directly affect yield stress of a slurry, possibly as a result of a reduction in particle

193 size, as well as enhancing enzymatic hydrolysis due to the modification of the surface chemistry

194 of the particles [21, 27]. While a reduction in particle size lowers viscosity, as well as increases

195 conversion efficiency, the manner in which the size reduction occurs is also important. Size

196 reduction via pretreatment provides better digestibility and a reduced yield stress as compared to

197 mechanical size reduction, which did not significantly impact either property [27]. In some

198 cases, the pretreatment, like dilute acid pretreatment, hydrothermal pretreatment or SPORL

199 (sulfite pretreatment to overcome recalcitrance of lignocelluloses) performed prior to the

200 hydrolysis step alters the structure of the biomass significantly so that liquefaction occurs

201 quickly upon addition of the enzymes and mixing can resume [28, 29]. However, in most cases,

202 the solid fraction is still a complex network of fibrous material $[21,24,30]$. Sufficient mixing is

203 required for timely hydrolysis of the biomass, and traditional mixing methods like stirred-tank

204 reactors with impellers require excessive power and shaking does not provide adequate mixing.

205 Several mixing alternatives are discussed in a later section.

206 The pulp and paper industry has long used additives to modify rheological properties of

207 lignocellulosic slurries [25]. Knutsen and Liberatore [31] found that the most effective additive

208 groups (in descending order) to reduce yield stress were surfactants, additives with polar head

209 groups, additives with hydrophobic tails, unmodified protein and polymers. CTAB (cetyl

210 trimethylammonium bromide) and $\mathrm{CPCl}$ (cetylpyridinium chloride), both surfactants, were two

211 of the most effective additives for reducing yield stress. Samaniuk et al. [25] used water soluble

212 polymers (WSPs) like carboxymethyl cellulose (CMC), polyethylene oxide (PEO) and

213 polyacrylamide (PAM), to modify rheological properties of lignocellulosic slurries. Additives

214 like CMC reduced the friction between cellulose surfaces, making it easier to mix high-solids 
215 suspensions. The addition of $2 \% \mathrm{CMC}$ reduced the yield stress by $\sim 67 \%$ from $55 \mathrm{kPa}$ to $\sim 18$

$216 \mathrm{kPa}$. A four-fold increase in CMC resulted in reducing by another $50 \%$. They also found that a

217 lower degree of substitution for CMC had a positive impact on the yield stress; however, this

218 trend was more apparent at higher CMC loadings. Furthermore, a reduction in yield stress was

219 observed as the molecular weights of the WSPs increased up to a certain point. For example,

220 yield stress decreased with the addition of $600 \mathrm{kDa}$, as well as $2000 \mathrm{kDa}$, PEO, but no further

221 change in yield stress was observed with the addition of $7000 \mathrm{kDa}$ PEO. Several other additives

222 were screened by monitoring the reduction in torque as measured by a torque rheometer to

223 determine whether they warranted further investigation. Fly ash and microcrystalline cellulose

224 were evaluated as possible additives, but their impact was limited. The surfactant Polysorbate 80

225 reduced the yield stress by $36 \%$ but required high concentrations (10\%). Guar gum,

226 hydroxypropyl methyl cellulose (HPMC), a guar gum-xanthan gum mixture and a guar gum-

227 HPMC mixture were all more effective than CMC, where guar gum and the two mixtures

228 containing guar gum resulted in the highest reduction in torque $(\sim 80 \%)$. The addition of

229 additives may be costly, but like the pulp and paper industry, it may become economically

230 feasible to utilize such methods of modification for high-solids conversion processes. It is

231 important, however, that these additives be as inexpensive as possible and do not negatively

232 impact the conversion process by inhibiting the hydrolytic enzymes or fermentative organisms.

\section{4. Impacting Enzymatic Hydrolysis Rate and Extent}

235 The term "lignocellulosic biomass" refers to many different types of biomass, including

236 forestry and agricultural residues (woody biomass, straw, stover), fermentation by-products

237 (DDGS) and dedicated energy crops (grasses), just to name a few. Each type of lignocellulosic 
material is slightly different in regards to composition, resulting in unique challenges in the

239 enzymatic hydrolysis step of the conversion process. The following sections are organized based

240 on various aspects in need of consideration during the conversion of lignocellulose and highlight

241 some of the challenges and breakthroughs associated with enzymatic hydrolysis performed at

242 high-solids loadings for different types of biomass. It is important to note that while each of

243 these processing approaches are discussed individually, it is often difficult to separate out the 244 combined effects of multiple process conditions.

245 Furthermore, when determining cellulose conversion, it is important to note that the

246 standard method of calculating conversions as described by [32] can grossly overestimate actual

247 conversion for high-solids systems. In some instances, conversions can be overestimated by up

248 to $36 \%$ [5]. Determining cellulose conversion in high-solids systems can become very

249 complicated, but several studies have proposed new methods for determining cellulose

250 conversion $[5,33,34]$ under these high solids operating conditions. The standard method for

251 conversion calculations typically compares the amount of glucose measured in the hydrolyzate

252 (the liquid fraction) to the potential glucose found in the biomass (the solid fraction). This

253 method requires the assumption that all components have a consistent density throughout the

254 reaction and that it is approximately equal to that of water. As solids loadings increase, this

255 assumption no longer remains valid, resulting in overestimated conversions.

\section{4.1 Biomass Processing}

258 Enzymatic hydrolysis is an intermediate step in the conversion process, and while

259 producing high sugar yields is favorable, the resulting hydrolyzate must be subsequently capable 260 of supporting fermentative organisms while they produce biofuels. Some of the more expensive 
261 steps in substrate preparation are washing the substrate following pretreatment and detoxifying

262 the hydrolyzate produced during enzymatic hydrolysis. It is likely that for industrial processes

263 unwashed, whole slurries (liquid + solids) from pretreatment will be used in enzymatic

264 hydrolysis [2], indicating a need for robust enzymes capable of maintaining their activity in the

265 presence of possible inhibitors and degradation products or developing pretreatments that do not

266 produce such products. Furthermore, the cost of hydrolyzate detoxification alone can be up to

$26722 \%$ of the total ethanol production cost [35].

268 Several studies have investigated the effects of eliminating washing and/or detoxifying

269 steps in the lignocellulose conversion process, with some promising results. Hodge et al. [2]

270 studied the effects of soluble and insoluble inhibitors on enzymatic hydrolysis by comparing the

271 glucose yields produced from a washed pretreated substrate (which introduces only potentially

272 insoluble inhibitors into the hydrolysis reaction since all soluble inhibitors are washed away) and

273 an unwashed whole slurry substrate (which introduces both potentially soluble and insoluble

274 inhibitors to the hydrolysis reaction). However, to maintain the high-solids loading and modify

275 the $\mathrm{pH}$, the solid and liquid fractions were separated, the liquid fraction $\mathrm{pH}$ was adjusted, and the

276 two fractions were combined. Should the whole slurry be used at the industrial scale (as this

277 study states in its rationalization for this work), this method of $\mathrm{pH}$ modification may not be

278 feasible. This challenge is just one of many that must be solved prior to implementing a

279 complete conversion process. Regardless, this study utilized an insoluble solids loading of 5-

$28013 \%$ ( 9-24\% total solids loading) and relatively low enzyme loadings (<20 FPU/g cellulose).

281 Based on the glucose production from hydrolysis, the authors suggested that the limitations due

282 to mass diffusion are more prevalent than the sugar inhibition beyond a specific solid content.

283 For instance, sugar inhibition would result in a "leveling-off" of the hydrolysis rate, much like 
284 what would be seen in a typical hydrolysis curve. However, a sharp decrease in the hydrolysis

285 rate was reported here. Using the washed substrate, this decrease is not prevalent until $20 \%$

286 insoluble solids loadings are reached, where convective mixing and available water are

287 negligible, likely indicating the point of mass transfer limitations. This decrease occurs at much

288 lower solids loadings ( $<10 \%$ insoluble solids) for unwashed substrate, indicating that the soluble

289 components contributed to a higher rate of enzyme inhibition or limited mass transfer by

290 reducing the amount of water available for reaction. (Further discussion on the restriction of

291 water can be found in Section 4.4 Solids Effects.)

292 Pristavka et al. [36] also conducted enzymatic hydrolysis studies with $\mathrm{SO}_{2}$-catalyzed

293 steam exploded willow. These studies were concerned with simplifying the conversion process

294 by neglecting to wash the pretreated willow between the pretreatment and hydrolysis steps and

295 eliminating mechanical stirring of the biomass slurry. The reason for eliminating the washing

296 step was two-fold. First, less water would be used in the conversion process, making the process

297 more economical and more environmentally friendly. Secondly, washing usually leads to the

298 solubilization and removal of a significant portion of sugars. These sugars ultimately end up

299 accumulating in wastewater, resulting in an expensive processing step to recover them and/or

300 treating the water. The high-solids loadings (up to $25 \%$ ODM (organic dry matter)) used in this

301 study would make mechanical stirring of the slurry extremely energy intensive, so it was

302 removed. With these process modifications, a lower degree of conversion was observed as

303 compared to biomass that was washed prior to hydrolysis (53\% vs. $74 \%$ ). However, the degree

304 of cellulose conversion increased to $>95 \%$ when the $\mathrm{pH}$ of the unwashed, pretreated willow was

305 adjusted with solid $\mathrm{NaOH}$ to the optimal $\mathrm{pH}$ of the enzymes. The significant increase in

306 conversion following $\mathrm{pH}$ adjustment highlights the importance of maintaining optimal hydrolysis 
307 conditions for the enzymes, even if that means finding new, inexpensive and less resource308 intensive methods of doing so.

$309 \quad$ Lu et al. [37] investigated the effects (post-pretreatment) washed substrate had on 310 enzymatic hydrolysis and fermentation. Using steam-exploded corn stover, substantial

311 differences in conversion efficiencies were not observed for washed and unwashed substrates up 312 to a solids loading of $30 \%(\mathrm{w} / \mathrm{w})$. However, closer examination of the conversion calculations 313 revealed differences between washed and unwashed substrates, since conversions were based on 314 water insoluble solids and not total solids content. (Essentially the denominators were different

315 for the two treatments.) Additionally, the $\mathrm{pH}$ of the unwashed corn stover was not adjusted prior 316 to addition of enzymes and buffer at $\mathrm{pH}$ 4.8. Cellulose conversion remained fairly consistent 317 (70-75\%) for all solids loadings, although glucose content was higher for the washed substrate 318 than the unwashed substrate. Ethanol production was also independent of solids loading (up to $31930 \% \mathrm{w} / \mathrm{w}$ ) for the water-washed corn stover, reaching 92-94\% of theoretical yield. However, the 320 results were quite different for the unwashed substrate. At the lower solids loadings studied (10$32115 \% \mathrm{w} / \mathrm{w}$ ), ethanol production fell to $88 \%$ and $86 \%$, respectively, and decreased as the solids 322 loading increased, until no ethanol could be measured ( $\geq 25 \%$ solids loading). The levels of 323 acetic acid and furfural measured at the higher solids loading reached inhibitory concentrations.

324 Inclusion of the water-washing step following pretreatment appears to eliminate the need for 325 another costly detoxification step following enzymatic hydrolysis for steam-exploded corn 326 stover.

327 In contrast to this study, others report contradicting results regarding the wash step [35, 328 38]. Lau et al. [35] reported that when AFEX-pretreated corn stover was fermented following 329 enzymatic hydrolysis at $18 \%$ (w/w) solids loading, the ethanol yield of $\sim 93 \%$, even though the 
330 solids loading during hydrolysis and glucose concentration before fermentation were similar to

331 those reported in Lu et al. [37] who reported a $68 \%$ ethanol yield. While these results are so

332 different, it should be noted that different pretreatments, as well as fermentative organisms were

333 used (E. coli vs. S. cerevisiae, respectively), making it difficult to directly compare these

334 fermentation results. However, Lau and Dale [38] achieved higher ethanol production rates

335 fermenting unwashed substrates ( $\sim 0.17 \mathrm{~g} / \mathrm{L} / \mathrm{hr}$ as compared to $0.12 \mathrm{~g} / \mathrm{L} / \mathrm{hr}$ for washed substrate)

336 with S. cerevisiae 424A (LNH-ST) (a genetically modified strain for improved xylose

337 fermentation), suggesting that the elimination of the washing step following pretreatment, and

338 with no adjustments made to the $\mathrm{pH}$ prior to hydrolysis, is beneficial for fermentation under the

339 conditions examined in this study. Ethanol concentration from unwashed substrate was $40 \mathrm{~g} / \mathrm{L}$

340 (no data given for washed substrate). Xylose metabolism from the genetically modified strain is

341 likely the largest contributing factor to the discrepancy in reported ethanol yields, but it was also

342 reported that the this strain of S. cerevisiae performed similarly on washed substrate as compared

343 to unwashed substrate. This study suggests that the washing step can be eliminated without any

344 loss in ethanol yield. Contradictory results indicate the need for further study of this issue, or at

345 the very least, optimization studies under specific process conditions.

346 In another study, LHW-pretreated sweet sorghum bagasse was hydrolyzed at 15-30\%

347 solids (w/v) with either 20 or $30 \mathrm{FPU} / \mathrm{g}$ glucan cellulase [39]. Washing the substrate prior to

348 hydrolysis also did not improve the conversion rates. Washed substrate yielded $63.2 \mathrm{~g} / \mathrm{L}$ of

349 sugar, whereas the unwashed substrate resulted in a sugar concentration of $66.1 \mathrm{~g} / \mathrm{L}$. It was

350 suggested, although not verified, that the washing step actually removed some of the smaller

351 cellulose particles that may have been easier to hydrolyze than larger cellulose particles. 
The inconclusive results of these studies illustrate the complexity of defining appropriate

353 processing conditions that work in all situations. Operating conditions must be chosen carefully

354 in order to realize the full potential of using lignocellulose as a valuable energy source. Table I

355 illustrates the wide variety of operating conditions that have been studied with regards to high-

356 solids loadings enzymatic hydrolysis. Depending on various factors, like substrate choice,

357 pretreatment conditions and hydrolysis conditions, it may be possible to eliminate certain steps

358 like washing pretreated substrate or detoxifying hydrolyzate prior to fermentation, thus

359 simplifying the overall conversion process. However, elimination of these steps may present

360 new problems that must be solved. For instance, should the washing step following pretreatment

361 be eliminated, it may be necessary to adjust the $\mathrm{pH}$ in another manner so the hydrolytic enzymes

362 can work most effectively.

\section{$364 \quad 4.2$ Feeding Strategies}

365 Fed-batch feeding schemes have been investigated as an alternative method of achieving

366 high-solids loadings in enzymatic hydrolysis $[1,26,45,46]$ because of some of the advantages it

367 offers over single feeding schemes. For instance, the initial viscosity is lower, so diffusion and

368 mixing limitations can be minimized or altogether avoided. A fed-batch feeding regime also

369 allows time for the slurry to liquefy before adding additional solids, which maintains a level of

370 free water that is available for the reaction process and for diffusion (away from the enzymes) of

371 potentially inhibitory products that result from the hydrolysis reaction. However, when a fed-

372 batch approach is selected, one must consider how and when to add substrate, as well as

373 enzymes, to the reaction in order to maintain high rates of conversion. Table II illustrates the

374 variety of substrate and enzyme application rates used in fed-batch studies. 
376 to achieve a final insoluble solids content of $15 \%(\mathrm{w} / \mathrm{w})($ equivalent to a $25 \%(\mathrm{w} / \mathrm{w})$ initial solids

377 loading). This solids loading was the upper limit of unhydrolyzed pretreated corn stover that

378 could be effectively mixed in the stirred tank reactors (STRs) available to the researchers. High

379 cellulose conversion (>80\% cellulose conversion) was reported; however, the reaction time was

380 more than double the typical hydrolysis reaction time (168 hrs vs. $72 \mathrm{hrs}$ ). The extended time

381 problem may be overcome through the use of higher enzyme loadings or enzymes that can

382 tolerate higher sugar concentrations. The enzyme loading used in this study was $10.7 \mathrm{FPU} / \mathrm{g}$

383 cellulose, a relatively low loading, and it was applied proportionally with each addition of

384 substrate. A study conducted by Yang et al. [46] obtained a similar cellulose conversion

385 (70.6\%), with a higher solids loading (30\%), an enzyme loading almost twice (20 FPU/g

386 cellulose) that used in the former study and with a much shorter reaction time (30 hrs). Both

387 studies attribute the high conversion rate, at least in part, to the fact that the substrates were

388 washed prior to hydrolysis, possibly eliminating any potential inhibitory products that resulted

389 from the pretreatments. The latter study also supplemented fresh enzyme with each addition of

390 new biomass, which increased the final enzyme loading from 10 to $15 \mathrm{FPU} / \mathrm{g}$ cellulose. The

391 fresh enzyme may have also enhanced the glucose yield, replacing the enzyme that may be non-

392 productively bound to the lignin or deactivated by extended hydrolysis times.

393 Zhang et al. [52] studied another fed-batch approach for the conversion of $\mathrm{NaOH}$ -

394 pretreated sugarcane bagasse and wheat straw. Pretreated biomass was fed into the reactor at $3959 \%, 8 \%, 7 \%$, and $6 \%$ solids over the course of $48 \mathrm{hrs}$ to achieve a final solids loading of $30 \%$

396 (w/v). All enzymes were added with the first addition of lignocellulose. Glucose conversion

397 from wheat straw reached a maximum ( 60\%) after the first feeding, but decreased with each 
successive feeding. The higher rate of conversion was likely due to the low solids loading and

399 high enzyme loading at the beginning of the reaction. With each successive feeding, the

400 enzyme: substrate ratio decreased. After $72 \mathrm{hr}$ of hydrolysis, the conversion began to level off,

401 resulting in a final glucose conversion of 39\%. A slightly different conversion profile was

402 observed with the bagasse. The conversion continued to increase over the course of the

403 hydrolysis reaction, with the exception of the last feeding time ( $6 \%$ solids at $48 \mathrm{hr}$ ). The final

404 feeding resulted in a sharp decrease in conversion, but it recovered within $24 \mathrm{hr}$ following the

405 feeding, leading to an increase in conversion over the batch. The final glucose conversion of the

406 sugarcane bagasse was 55\%. Differences in the way the pretreatment affected the lignocellulose

407 may have led to the different glucose yields between the two substrates. It was reported that the

408 pretreatment caused the surface of the two substrates to become rough and fragmented as lignin

409 was removed, allowing for better access to the cellulose; however, the bagasse appeared to have

410 a rougher, more fragmented surface than the wheat straw. Following $144 \mathrm{hr}$ of hydrolysis, the

411 surfaces were relatively smooth as compared to the start of the hydrolysis.

412 Wang et al. [39] considered the use of a fed-batch feeding scheme. Initially, the reactors

413 were charged with half of the final solids loading, followed by two additional feedings at 24 and

$41448 \mathrm{hr}$ of one-fourth of the final solids loading. The system containing $30 \%$ solids achieved the

415 highest final sugar concentration with nearly $115 \mathrm{~g} / \mathrm{L}$. Even with the fed-batch system, the

416 conversion decreased with increasing solids loadings; however, the conversion of the $30 \%$ solids

417 reaction was only $5 \%$ less than the systems at $15 \%$ and $20 \%$ solids (55\% vs. $~ 60 \%$,

418 respectively).

419 Fed-batch was utilized by Ma et al. [55] to achieve a 25\% (w/v) solids loading. Enzymes

420 were added either all at once at the beginning of the reaction or with each addition of the dilute 
421 acid pretreated cassava bagasse. At this solids loading, the batch reaction reached $\sim 50 \%$

422 conversion, whereas the fed-batches with a single enzyme addition and multiple enzyme

423 additions achieved $\sim 75 \%$ and $84 \%$ conversion, respectively. These results are similar to those

424 reported in other fed-batch studies [1,46], indicating that under the right conditions fed-batch

425 systems may be a plausible solution for achieving higher conversion rates for hydrolysis

426 performed at high-solids loadings.

$427 \quad$ Rosgaard et al. [26] investigated several different regimes for batch and fed-batch

428 hydrolysis, including variations of sequential addition of substrate as well as substrate plus fresh

429 enzyme. The addition of fresh enzyme with each substrate addition maintained a constant

430 enzyme:substrate ratio throughout the whole reaction, as opposed to the other fed-batch feeding

431 schemes where all the enzyme was added in one application. In these cases, the effective

432 enzyme:substrate ratio decreased with each subsequent addition of substrate. Not surprisingly,

433 the fed-batch schemes that received the full enzyme application at the start of the reaction

434 produced higher glucose yields during the first few hours as compared to the fed-batch reactions

435 that received fresh enzyme with each substrate addition. However, the extent of the hydrolysis

436 reaction was not affected by the method of enzyme application as the final glucose

437 concentrations were not different for the fed-batch reactions with and without additional enzyme

438 applications $(62-67 \mathrm{~g} / \mathrm{L})$. Furthermore, lower viscosity is often touted as an advantage of fed-

439 batch systems over batch systems because mixing becomes easier as viscosity decreases. The

440 viscosities of the fed-batch systems in this study were lower than in the batch systems, but no

441 benefits were observed in regards to glucose production as the batch system at $15 \%$ solids

442 resulted in higher glucose production ( $78 \mathrm{~g} / \mathrm{L}$ ) after $72 \mathrm{hr}$ hydrolysis. Final glucose

443 concentrations of the fed-batch systems, though, were impacted by each addition of substrate. 
444 Hydrolysis rates decreased and never fully recovered, resulting in lower final yields than the 445 batch systems.

446 Additionally, Chandra et al. [45] reported on a fed-batch approach at a moderate solids

447 loading that did not perform as well as a single stage feeding approach. The total solids loadings

448 achieved for both feeding schemes was $10 \%$. Two enzyme loadings were tested (5 and 60

449 FPU/g cellulose), and at both loadings, the batch reaction produced the higher yields,

450 approximately $66 \%$ and $90 \%$ for steam-pretreated corn stover, respectively. However, when the

451 solids are fed at $24 \mathrm{hr}$ intervals, the respective yields are lower (approximately $55 \%$ and $80 \%$ )

452 and the hydrolysis rates slower. The authors suggest these reductions in yields and rates are the

453 result of non-productive binding of enzyme to xylan or lignin fractions of the substrate or the

454 inability of the enzyme to desorb from partially hydrolyzed substrate and find accessible

455 cellulose sites in the fresh substrate. Free protein measurements taken at $72 \mathrm{hr}$ indicate that 50-

$45670 \%$ of the cellulase was still adsorbed to the substrate for both enzyme loadings, while the

457 cellulose conversion ceased. The lower hydrolysis rate at the higher enzyme loading seems to

458 indicate that the enzymes are saturating the accessible cellulose sites, thus reaching a maximum

459 hydrolysis rate that is lower than that of the batch reaction when all the accessible cellulose sites

460 are available at once.

461 The results of fed-batch feeding schemes are currently still inconclusive, as indicated by

462 the preceding studies, making the decision to use a fed-batch approach unclear. Many

463 advantages are realized regarding the use of fed-batch systems, but questions persist. For

464 instance, at what point in the reaction should subsequent additions of substrate be applied to

465 maintain a high rate of conversion? Should enzymes be added in a single application, as a

466 supplement to the original application, or proportionally to the substrate? Does the benefit of 
467 reduced viscosity make a difference in energy consumption during the conversion process to

468 overcome the potentially reduced sugar yield that may result from the fed-batch as compared to

469 the batch system?

\section{$471 \quad 4.3$ Effects of Enzyme Synergism}

472 Enzymatic hydrolysis, especially at high-solids loading, has been identified as the largest

473 impediment to achieving high yields in a timely manner in the lignocellulose to ethanol

474 conversion process, mainly because a significant portion of sugars produced are in oligomeric or

475 polymeric form, which cannot be used in the fermentation process. Several studies have

476 investigated this issue from the perspective of the enzyme (Table I), experimenting with enzyme

477 supplementation (in addition to cellulase) and alternative organism sources for cellulase [38, 47-

478 49]. Supplementing cellulase with $\beta$-glucosidase has long been used to minimize end-product

479 inhibition of the cellulase and achieve higher conversions. Lau et al. [48] investigated the use of

480 several different enzymes other than cellulase and $\beta$-glucosidase to enhance the conversion of

481 lignocellulose. Their enzyme cocktail included xylanase and pectinase to target the

482 hemicellulose that acts as a barrier to cellulose if not removed during pretreatment. The focus of

483 this work was on the fermentation step, so the details regarding the enzymatic hydrolysis are

484 limited. However, the hydrolyzates produced from AFEX-pretreated corn stover with these

485 enzyme cocktails were able to produce $40 \mathrm{~g} / \mathrm{L}(5.1 \% \mathrm{v} / \mathrm{v})$ of ethanol with Saccharomyces

486 cerevisiae.

487 Another study investigated the effects of supplementing the typical cellulase and $\beta$ -

488 glucosidase enzyme cocktail with xylanase on the hydrolysis of steam-exploded barley straw

489 [50]. The addition of the xylanase to the enzyme mixture enhanced the conversion rate of the 
490 cellulose, especially at low solids loading and early in the hydrolysis reaction. Conversion at 491 higher solids loadings may be reduced by the higher concentration of xylooligomers produced 492 with the addition of xylanases, as has recently been shown [15]. However, the xylanase used in 493 the supplementation study did contain some $\beta$-xylosidase activity, which, if present, might 494 counteract the inhibition caused by xylooligomers. The positive effects of the xylanase addition 495 reported in this study support the idea that overall enzyme loadings could be reduced if better 496 conversion is achieved by incorporating an array of different enzymes. However, a different 497 study conducted by Di Risio [44] also evaluated various enzyme cocktails made from 498 commercially-available enzyme solutions. All three cocktails assessed consisted of the same 499 base solution: cellulase and $\beta$-glucosidase. Each solution was supplemented with a third 500 commercial enzyme solution with different active components: cellulase + xylanase, cellulase + 501 xylanase $+\beta$-glucosidase, and xylanase. The highest glucose yields $(44 \%)$ resulted from the 502 enzyme cocktail consisting of the base solution supplemented with the commercial solution 503 containing cellulase + xylanase $+\beta$-glucosidase activity. Surprisingly, the enzyme solution 504 supplemented with the enzyme promoted as a "xylanase" actually yielded significantly less 505 xylose than the other two enzyme solutions (39\% as compared with $54 \%$ and $85 \%$ ). However, 506 there is no indication that the xylanase activity of this commercial product was independently 507 verified prior to use. Glucose yields ranged from $32 \%-42 \%$. Taking it a step further, another group studied the effects of various addition schemes and 509 enzyme loadings using an enzyme cocktail containing cellulase, $\beta$-glucosidase and xylanase on 510 the hydrolysis of mixed hardwood chip pulps [42]. The enzyme cocktails consisted of fungal 511 cellulase (C), xylanases (X) and $\beta$-glucosidase (B) solutions mixed in the ratio of 10:3:3 (by 512 volume). The mixtures were added to the substrate in the following manners: (1) cellulase, 
513 xylanases and $\beta$-glucosidase was mixed with substrate at the desired solids loading (CXB); (2)

514 cellulase was added to 5\% solids, pressed or filtered to obtain the desired solids loading, and

515 hydrolyzed for a period of time before the xylanases and $\beta$-glucosidase mixture was added

$516(\mathrm{C}+\mathrm{XB})$; and (3) half of the cellulase was added to $5 \%$ solids, pressed or filtered to obtain the

517 desired solids loading, and hydrolyzed for a period of time before the cellulase (half dose),

518 xylanases and $\beta$-glucosidase mixture was added $(\mathrm{C}+\mathrm{CXB})$. With the $\mathrm{CXB}$ mixture, a decrease in

519 conversion was observed with an increase in solids loading. Enzyme loading also plays an

520 important role in the optimization of biomass conversion. For example, with the CXB enzyme

521 mixture, the difference in sugar yields decreased with increased enzyme loadings. At 40 FPU/g

522 solids, conversion decreased from $70 \%$ to $68 \%$ for $5 \%$ and $20 \%$ solids loading, respectively,

523 which represents no significant difference in conversion. However, at $5 \mathrm{FPU} / \mathrm{g}$ solids,

524 conversion decreased from $40 \%$ to $19 \%$ for $5 \%$ and $20 \%$ solids loadings, respectively. The

525 authors hypothesized the decreased conversion was the result of ineffective mixing of the

526 enzyme mixture with the substrate as the solids loadings increased. Based on this hypothesis, the

527 authors added the enzyme to a low solids mixture, allowing time for the enzymes to adsorb to the

528 substrate, before filtering off $80 \%$ of the liquid to obtain $20 \%$ solids loadings. Enzyme activity

529 was tested following filtration to determine whether any enzyme was lost during this process.

530 Cellulase activity registered at $80 \%$ of the original activity, whereas only $20 \%$ of the xylanases

531 activity was retained. This observation resulted in the modified application of the enzyme

532 mixture $(\mathrm{C}+\mathrm{XB})$. At $20 \%$ solids and $20 \mathrm{FPU} / \mathrm{g}$ solids, sugar conversion increased from $44 \%$ for

533 the $\mathrm{CXB}$ mixture to $59 \%$ for the $\mathrm{C}+\mathrm{XB}$ mixture. Sugar concentrations increased from $84 \mathrm{~g} / \mathrm{L}$ to

$534114 \mathrm{~g} / \mathrm{L}$. This modified enzyme application process was also beneficial at low solids loadings

535 (5\%), increasing conversion from $19 \%$ with $\mathrm{CXB}$ to $38 \%$ with $\mathrm{C}+\mathrm{XB}$. Taking this enzyme 
536 application process one step further, additional cellulase was added with the xylanases and $\beta$ -

537 glucosidase mixture $(\mathrm{C}+\mathrm{CXB})$. In this instance, although the sugar concentration increased to

$538121 \mathrm{~g} / \mathrm{L}$ glucose ( $63 \%$ conversion), the conversion at $20 \%$ solids was similar to that at $5 \%$ solids

539 at all enzyme loadings tested. These experiments indicate the importance of determining enzyme

540 mixtures and application schemes that provide the optimal sugar yields and concentrations for

541 the conversion process.

542 Along with the feeding scheme and the enzyme loading, the type of enzyme used can

543 have a significant impact on the liquefaction of biomass. The term "cellulase" can refer to a

544 wide variety of enzymes, and commercially available enzymes can often be a crude mixture of

545 enzymes (i.e. $T$. reesei cellulase that is commonly used in hydrolysis studies). To be more

546 specific, for example, the T. reesei "cellulase" can refer to a mixture of cellobiohydrolases

547 (CBH), endoglucanases (EG), xylanases (XYLs), and $\beta$-glucosidase, among other enzyme

548 components. Using an array of CBHs, EGs, XYLs and a $\beta$-glucosidase, both individually and in

549 combination, Sjizarto et al. [30] assessed the enzymes on their ability to liquefy hydrothermally

550 pretreated wheat straw. For the T. reesei components, it was determined that the EGs (especially

551 Cel5A) were the most important in liquefying lignocellulose. This enzyme alone reduced the

552 viscosity of the slurry by nearly $90 \%$. The CBHs and XYLs had little to no effect on the

553 viscosity, even though the sugar production was similar to that of some of the EGs.

554 Furthermore, a mixture of enzymes produced the highest sugar yields, even though the viscosity

555 was reduced by only about $82 \%$, indicating that the amount of sugar hydrolyzed is not the main

556 factor in reducing viscosity, but that the sites at which the polysaccharides are cleaved is more

557 important. 
Since enzymes play such a vital role in the conversion of lignocellulose, much of the

559 process integration depends on these biological catalysts. For instance, a balance must be struck

560 between the enzyme loading used and enzyme cost. High enzyme loadings not only increase the

561 total cost, but as discussed in the introduction, studies suggest that enzymes are overcrowding

562 accessible cellulose chains, thus reducing the rate at which cellulose is hydrolyzed. One such

563 study was conducted by Olsen et al. [58]. At a solids loading of 29\% (w/w) pretreated corn

564 stover, a range of enzyme loadings (5-83 FPU/g cellulose) were evaluated for hydrolysis yields.

565 At enzyme loadings >66 FPU/g cellulose, the hydrolysis curves started to coincide. It was

566 suggested that the lack of improvement in hydrolysis rate and conversion was due to the

567 substrate being completely saturated with enzymes bound to all the accessible sites. High

568 enzyme loadings also do not make sense economically. Based on a techno-economic model of

569 the bioethanol conversion process, an optimum total solids loading of about $20 \%$ with an enzyme

570 loading of $20 \mathrm{mg} / \mathrm{g}$ solids (8.8 FPU/g solids) was determined to produce the minimum ethanol

571 selling price with currently available, commercial enzymes [4]. This model evaluated the cost of

572 production at 2007 enzyme production costs $(\$ 0.35 / \mathrm{gal})$, as well as the enzyme production cost

573 projected by the Multi-Year Program Plan (MYPP) from the DOE's Office of Biomass Program

574 for 2012 (\$0.12/gal) [59]. At the lower enzyme production cost, solids loadings could

575 potentially be increased up to $26 \%$ and remain economically viable. In the time since this study

576 was published, the MYPP re-evaluated the cost of enzyme production and the current projection

577 for 2012 was fairly consistent with the "high" cost of enzyme production reported in the study at

$578 \$ 0.34 /$ gal of ethanol (2007\$). Under the assumptions made constructing this model, $20 \%$ solids

579 loading remains the maximum that is economically feasible for the ethanol production process. 
581 concentration. A 50\% reduction in enzyme loading decreased the glucose concentration by only

$58221 \%$. The implication of this observation is that enzyme loading can be optimized to provide the

583 maximum concentration at the lowest unit cost. For example, it may not be worth converting an

584 extra $5 \%$ of glucose if it accounts for $\sim 15 \%$ of the total enzyme cost unless the return on the

585 extra glucose recovers the cost of the additional enzyme.

While the cellulase system of $T$. reesei is one of the most commonly studied enzyme

587 systems, other organisms also produce cellulolytic enzymes that could potentially impart

588 superior activity under certain conditions. Ingram et al. [53] compared the conversion

589 efficiencies of enzymes from two different organisms, T. reesei and a genetically-modified (for

590 increased cellulase production) strain of Penicillium janthinellum. Enzyme mixtures from both

591 organisms contained cellulases, $\beta$-glucosidases and xylanase activity. With the cellulase from $T$.

592 reesei, an increase in glucose concentration as biomass loading increased was observed for the

593 organosolv and the LHW-pretreated rye straw. After $48 \mathrm{hrs}$ of hydrolysis at $17.5 \%$ solids, the $P$.

594 janthinellum cellulase converted $72 \%$ of the soda-pretreated rye straw. Higher enzyme loadings

595 of $P$. janthinellum cellulase were necessary to achieve the same level of conversion produced by

596 the $T$. reesei cellulase (27 FPU/g cellulose vs. 13 FPU/g cellulose); however, the P. janthinellum

597 cellulase appeared to be more tolerant to changes in $\mathrm{pH}$. This study highlights the fact that the

598 conversion process is dependent on many factors, including, but not limited to, the type of

599 biomass, the conditions of the pretreatment, and the source of enzymes.

600 In another study partially purified cellulase from the thermostable Geobacillus R7 was

601 evaluated as an alternative cellulase source [47]. For short hydrolysis times (36 hr), the

602 Geobacillus cellulase was comparable to a commercial enzyme preparation. However, for 
603 hydrolysis of pretreated prairie cord grass using this cellulase, the glucose recovery at $96 \mathrm{hrs}$ for 604 solids loadings $\geq 10 \%$ was between $46.2 \%$ and $48.7 \%$. It does not appear that the solids loading 605 had much of an impact on conversion of the prairie cord grass; although the conversion of 606 cellulose into glucose utilizing the Geobacillus R7 cellulase was better than the conversion of the 607 pretreated corn stover at 27\%-31\%. Geobacillus $\mathrm{R} 7$ also has the added benefit of being 608 ethanologenic. During the hydrolysis, Geobacillus R7 produced a small amount of ethanol $609(0.035 \mathrm{~g} / \mathrm{L})$ from the pretreated prairie cord grass, which has possible implications for 610 consolidated bioprocessing of lignocellulose materials. Subsequent fermentation of the 611 hydrolyzate with S. cerevisiae resulted in an ethanol production of $7.8 \mathrm{~g} / \mathrm{L}$ (or $0.47 \mathrm{~g}$ ethanol/g 612 glucose) for the $20 \%$ solids loading of prairie cord grass.

613 Lastly, Matano et al. [60] engineered fermentative yeast to express three different types 614 of cellulase on its surface. This yeast was subsequently evaluated in SSF processes utilizing $61525 \%(\mathrm{w} / \mathrm{v})$ pretreated rice straw. Initially, a control yeast strain was supplemented with a 616 commercial cellulase (100 FPU/g biomass). This combination resulted in an ethanol yield of

$61780 \%$ and liquefaction after $72 \mathrm{hr}$. When combined with the modified yeast strain, the 618 commercial cellulase loading could be reduced to $10 \mathrm{FPU} / \mathrm{g}$ biomass and produce the same 619 ethanol yield (79\%). Further study showed that a maximum ethanol concentration (43.1 g/L) 620 was obtained following a $2 \mathrm{hr}$ liquefaction period prior to the addition of the modified yeast, 621 corresponding to an ethanol yield of $89 \%$. Residual glucose was reduced by an order of 622 magnitude with the modified strain $(16 \mathrm{~g} / \mathrm{L}$ to $1.6 \mathrm{~g} / \mathrm{L})$. The authors hypothesized that the close 623 proximity of the cellulases on the surface of the yeast provided a synergistic effect that resulted 624 in an increased hydrolysis of cellulose. As commercial enzymes are still a relatively large 625 portion of the overall cost of the conversion process, the ability to reduce the commercial 
626 enzyme loading and replace it with an organism capable of both the hydrolysis and fermentation

627 is very attractive.

\section{$629 \quad$ 4.4 Solids Effect}

For conversion of lignocellulose into usable and valuable products, it makes economical

631 sense to utilize locally-available biomass, as shipping biomass over long distances greatly

632 reduces the beneficial impacts. Cara et al. [41] studied the conversion of olive tree pruning

633 biomass (consisting of leaves and thin branches) up to $30 \%$ (w/v) solids loadings. The final

634 glucose concentrations increased with increasing solids loading, achieving $61 \mathrm{~g} / \mathrm{L}$ and $52 \mathrm{~g} / \mathrm{L}$

635 glucose at $30 \%$ solids loading of the liquid hot water (LWH) pretreated biomass and steam

636 exploded biomass, respectively. However, the conversions of the LHW-pretreated biomass

637 decreased nearly linearly from $76.2 \%$ at $2 \%$ solids to $49.9 \%$ at $30 \%$ solids. Conversions of the

638 SE-pretreated biomass held steady between $60 \%$ and $63 \%$ up to $10 \%$ solids loading before

639 decreasing to $39.6 \%$ at $30 \%$ solids. In a different study, the researchers also observed that the

640 glucose concentration decreased as the solids loading was increased beyond $10 \%$ solids for the

641 soda pretreated rye straw [53]. The overall conversion of cellulose decreased from $\sim 65 \%$ to $40 \%$

642 as solids loadings increased from $\sim 10 \%$ to $17.5 \%$. This result is not unusual, as most studies

643 performed at high-solids loadings sacrifice conversion for a more concentrated glucose product

$644[10,29,41]$

645 Kristensen et al. [10] also studied four mechanisms that possibly contribute to the so-

646 called solids effect: (1) compositional and substrate effects, (2) product inhibition, (3) water

647 concentration, and (4) cellulase adsorption. These mechanisms were studied with filter paper,

648 which is essentially a pure cellulose substrate. The researchers observed the same decreasing 
trend in conversion as solids increased using the filter paper, much like that observed with

650 lignocellulose. Therefore, it was concluded that lignin, which is absent in filter paper, is likely

651 not the reason for the solids effect. Study of the second mechanism, product inhibition, resulted

652 in significantly different conversions after 48 hours of hydrolysis for 5\% DM and 20\% DM

653 (64.5\% vs. $38.6 \%$ or $30 \mathrm{~g} / \mathrm{L}$ vs. $86 \mathrm{~g} / \mathrm{L}$, respectively). However, the final conversions for these

654 solids loadings with an additional $50 \mathrm{~g} / \mathrm{L}$ glucose added resulted in fairly similar conversions

655 (29.7\% and $26.3 \%$ or $64 \mathrm{~g} / \mathrm{L}$ vs. $109 \mathrm{~g} / \mathrm{L}$ for $5 \% \mathrm{DM}+50 \mathrm{~g} / \mathrm{L}$ glucose and $20 \% \mathrm{DM}+50 \mathrm{~g} / \mathrm{L}$

656 glucose, respectively). This experiment did not elucidate the exact reason for the observed

657 similar conversions, but two hypotheses were offered. It was suggested that other components in

658 the hydrolysis mask the product inhibition or that enzymes are inhibited similarly once a certain

659 glucose concentration is reached.

660

Kristensen et al. [10] next attempted to quantify the effects of water on the hydrolysis

661 reaction. Water content was decreased by $25 \%$ and replaced by oleyl alcohol. The alcohol

662 allowed the viscosity of the slurry to remain constant, thus removing the effects of the viscosity,

663 while the water to solids (or enzyme) ratio was altered. With this decrease in water, a 5\%

664 decrease in glucose yield was observed. However, increasing the solids content from $20 \%$ to

$66525 \%$ (which is essentially equivalent to a $25 \%$ reduction in water), typically decreases glucose

666 yields by $\geq 12 \%$. The authors argue this discrepancy in glucose reduction indicates that lower

667 water content is apparently not the limiting factor responsible for the solids effect.

668 Lastly, cellulase adsorption was investigated as a possible source of the solids effect [10].

669 Cellulase adsorption to filter paper was determined by measuring the total nitrogen content of the

670 biomass after $24 \mathrm{hr}$ of hydrolysis. The amount of adsorbed cellulase measured was halved (40\%

671 to $17 \%$ ) as solids loading increased from $5 \%$ to $25 \%$. At the same time, conversion was reduced 
672 from $\sim 60 \%$ to $<50 \%$. A strong correlation between decreasing adsorption and conversion was

673 observed, indicating that cellulase is not effectively adsorbing onto cellulose causing a decrease

674 in yield. The authors hypothesize that increasing concentrations of glucose and cellobiose inhibit

675 the adsorption of enzymes. Knowledge of the mechanisms of high-solids product inhibition and

676 the mechanisms of high-solids enzyme adsorption inhibition can provide the key to improving

677 the overall conversion process, thus unlocking the full potential of high-solids conversions.

678 In contrast to the previous study, Roberts et al. [56] investigated the interactions of water

679 with biomass at high-solids loading without maintaining a constant viscosity. Time domain

680 NMR was used to measure the transverse (or spin-spin) relaxation times $\left(\mathrm{T}_{2}\right)$ of protons in water

681 molecules to indicate the extent of water constraint (or degree to which water is tightly bound to

682 biomass). Essentially, the nuclei of water molecules that are tightly bound have a shorter

683 relaxation time than nuclei that are less tightly bound. By measuring these relaxation times,

684 constraint can be determined. It was found that water was more tightly bound as solids loadings

685 increased, suggesting that an indirect relationship between water constraint and yield exists.

686 However, the relaxation time of the primary bound water (water that interacts directly with the

687 surface of the cellulose) was constant regardless of the solids loading. Interactions at the water-

688 solids interface appear to remain constant, suggesting the chemistry at the surface of the

689 cellulose does not change as water content changes. These results further suggest that the water

690 primarily interacts with the cellulose, and the impact of the solute is minimized. However, these

691 studies were conducted with bacterial cellulose, a substrate that is essentially pure cellulose. It is

692 unclear whether cellulose derived from pretreated lignocellulose would interact with water in a

693 similar manner or to what extent the type of pretreatment may affect these cellulose-water

694 interactions. With the addition of excess glucose or mannose to 5\% solids, the hydrolysis rate 
695 reduced to one similar to $15 \%$ solids loading. The authors hypothesize that the negative effects

696 on the hydrolysis rate are caused by water constraint as opposed to the monosaccharides

697 impacting the enzyme activity. It is also possible that the lack of available water limited the

698 uniform distribution of synergistic enzymes, thus hindering the hydrolysis rate. Also, in contrast

699 to the previous study, the results presented in this study indicate that water (or the lack of it) has

700 a great impact on the overall hydrolysis rate. Even though the addition of oleyl alcohol in the

701 former study reduced the water content in the reaction, the constant viscosity helped maintain

702 adequate mixing and therefore did not limit the diffusion of enzymes throughout the suspension.

703 While these studies draw conflicting conclusions on the effect of water on lignocellulose

704 conversion, they do highlight the need for effective mixing. Adequate mixing was provided in

705 the former study, even with a low water: substrate ratio because of the low viscosity afforded by

706 the addition of alcohol, whereas the latter study simply reduced the water: substrate ratio without

707 regard for the viscosity. These studies also highlight the difficulty of quantifying and assigning

708 the challenges of operating at high solids to any one factor (lack of water, high viscosity,

709 adequate mixing, etc.) when all these factors are so interrelated.

710

$711 \quad 4.5$ Effect of Viscosity on Mixing

712 High viscosity of high-solids slurries is another hurdle that must be overcome. Much of

713 the previous discussion (i.e. effects of enzymes on liquefaction and solids loadings) also affects

714 the rheology, but this section discusses specific viscosity modifiers and their effects on

715 enzymatic hydrolysis. Ineffective mixing increases the limitations associated with mass transfer,

716 including removal of local inhibitors and hydrolysis products and transfer of heat throughout the

717 reactor. The pulp and paper industry has long been using viscosity modifiers to enhance the 
718 processability of fibrous slurries [31], much like the types of slurries produced by lignocellulose

719 materials prevalent in the conversion to biofuels and biochemicals. One study [31] investigated

720 the use of 18 different chemical additives and evaluated the effects on the slurry rheology and

721 hydrolysis rates. Several surfactants added to lignocellulosic slurries at 2\% (w/w), including

$722 \mathrm{CPCl}, \mathrm{CTAB}$, sodium dodecylbenzene sulfonate (NaDBS) and sodium dodecyl sulfonate (SDS),

723 positively affected the rheological properties of the slurry by reducing the viscosity by nearly

724 four-fold as compared to the viscosity of the unmodified slurry. Although slight decreases in the

725 extent of the hydrolysis reactions were observed, only the $\mathrm{CPCl}$ and the CTAB did not reduce

726 hydrolysis rates. Additionally, Ma et al. [55] tested the surfactant Tween-80 and found that it did

727 not produce a significant increase in conversion at a $10 \%$ solids loading to warrant its use.

728 However, at $25 \%$ solids loading, the addition of the surfactant $(2 \mathrm{~g} / \mathrm{L})$ increased cellulose

729 conversion by $30 \%$. Contrary to what Kristensen et al. [10] said, the inhibition caused by non-

730 productive binding of the enzyme to lignin does not seem to have as large of an effect at low

731 solids as it does at high solids. These results show some promise in modifying viscosity

732 properties of lignocellulose slurries; however, more work is warranted to understand the

733 mechanism by which these surfactants work, as well as determining the economical value of the

734 use of such additives.

735 Another approach to reducing viscosity is to raise the temperature at which the hydrolysis

736 reaction takes place [61]. In order to work at higher temperatures, enzymes that can tolerate the

737 increased temperatures must be used. It has been shown that EGs from more thermotolerant

738 organisms worked better at reducing the viscosity of a lignocellulose slurry, while other types of

739 enzymes appeared to have little effect [61]. T. aurantiacus proved to be more thermotolerant

740 than A. thermophilum, as the T. aurantiacus EG continued to reduce the viscosity at temperatures 
741 up to $75^{\circ} \mathrm{C}$. A. thermophilum enzymes were less active above $65^{\circ} \mathrm{C}$, resulting in a reduced effect

742 on the viscosity. The ability to use alternate sources of cellulase enzymes illustrates the number

743 of reaction condition variables (i.e. temperature, components in enzyme cocktail, and solids

744 content in slurry) open to modification.

745 The method of mixing the slurry can also have a substantial impact on the conversion of

746 lignocellulose. For example, Zhang et al. [43] observed a significantly reduced liquefaction time

747 when comparing hydrolysis at high solids $(17-20 \% \mathrm{w} / \mathrm{w})$ performed in shake flasks with a lab-

748 scale peg mixer. Peg mixers are commonly used in the pulp and paper industry, which routinely

749 utilizes solids loadings up to 35\% [43]. (Readers are referred to the section entitled "Reactor

750 design for enzymatic hydrolysis at high solids" for more details on the peg mixer.) Liquefaction

751 occurred after $1 \mathrm{hr}$ of hydrolysis in the peg mixer, whereas the shake flask required $40 \mathrm{hr}$. The

752 decrease in liquefaction time can most likely be attributed to the effective mixing provided by

753 the peg mixer and the breaking down of the large fiber network that tends to occur as solids

754 loadings surpass $8 \%$. At 20\% (w/w) solids loadings, hydrolysis performed in the peg mixer

755 resulted in $144 \mathrm{~g} / \mathrm{L}$ and $158 \mathrm{~g} / \mathrm{L}$ of glucose from unbleached hardwood and Organosolv

756 pretreated poplar, respectively. These concentrations are the highest glucose concentrations

757 achieved known to the authors at the time of writing this review.

758 One of the highest solids loadings in enzymatic hydrolysis reported to date is $40 \%$ (w/w)

$759[29,51]$. A horizontally-oriented rotating drum was utilized as the reactor in these studies in

760 order to effectively mix the solids. The studies found that cellulose and hemicellulose

761 conversion decreased from $\sim 90 \%$ to $\sim 33 \%$ and $\sim 70 \%$ to $35 \%$, respectively, with the increase in

762 solids loading from $2 \%$ to $40 \%$, but the reactor was providing adequate mixing as evidenced by

763 the conversion of lignocellulose into fermentable saccharides ( $86 \mathrm{~g}$ glucose $/ \mathrm{kg}$ at $40 \%$ solids) 
764 [29]. At 40\% solids, liquefaction occurred after only 4 hrs. The viscosity was still high, as the

765 slurry turned into a thick, clay-like paste and remained as a thick paste following $96 \mathrm{hrs}$ of

766 hydrolysis. Additionally, the reactor was a very energy efficient solution to the mixing problem.

767 Mixing speed did not affect the liquefaction time, so relatively low speeds (6.6 rpm) could be

768 used. It was also shown that ethanol could be produced in the same rotating drum reactor from

769 the resulting slurries, where the highest ethanol yield (48 g/kg DM) reported was from the slurry

770 at $35 \%$ solids. Even at reduced enzyme loadings (5 FPU/g DM supplemented with $\beta$-glucosidase

771 at a 5:1 loading), 40\% conversion for both cellulose and hemicellulose can be achieved at $30 \%$

772 solids loading [51]. These results suggest using one reactor for all processing steps in the

773 conversion of lignocellulose, with the implication that capital and equipment costs can

774 potentially be greatly reduced as both the number of reactors and amount of enzyme used

775 decreases. However, with the yield penalty for conversion at higher solids loadings being high, a

776 full techno-economic analysis would be needed to fully validate such a system operating under

777 the given conditions.

4.6 Tools and Methods for Measuring the Progress of Enzymatic Hydrolysis at High-Solids

$780 \quad$ Loadings

As more and more interest is expressed in the use of high-solids loadings in the

782 conversion of lignocellulose, it is also important that tools are available to properly measure and

783 study the progress of the hydrolysis reaction. Calorimetry has been studied as a new tool for

784 determining enzymatic kinetics of high-solids loadings in hydrolysis [58]. It provides higher

785 sensitivity than HPLC in the early stages of the hydrolysis, making calorimetry a useful tool to

786 evaluate initial rates of hydrolysis. Avicel showed that enzyme hydrolysis slowed when enzyme 
787 loading of $>30 \mathrm{FPU} / \mathrm{g}$ cellulose were used. It is believed that this reduction in rate is due to the

788 lack of available binding sites on the cellulose, as illustrated by the heat-flow curves converging

789 upon a single value, regardless of the enzyme loading.

790 Lavenson et al. [57] also implemented the use of new tools to monitor liquefaction and

791 the extent of hydrolysis of cellulose. Liquefaction and the spatial homogeneity of the enzyme

792 distribution in Solka-Floc suspensions $(28 \% \mathrm{w} / \mathrm{w})$ were monitored with magnetic resonance

793 imaging (MRI). The MRI signal is proportional to the amount of free water in the reaction,

794 which correlates to the degree of liquefaction in the system. Additionally, a penetrometer was

795 used to monitor the mechanical strength of the suspension. Measurements were taken on two

796 hydrolysis systems, where one contained a mixed Solka-Floc and enzyme suspension and the

797 other contained a Solka-Floc suspension that received an application of enzyme but no mixing.

798 Mechanical strength of the mixed suspension decreased by $20 \%$ of the initial strength after $\sim 30$

$799 \mathrm{hrs}$, as compared to $\sim 170 \mathrm{hrs}$ for the unmixed suspension. Based on the MRI results, the mixed

800 samples did not show a spatial gradient, indicating uniform liquefaction when the enzyme and

801 substrate are initially well-mixed. The unmixed samples showed a slow change in spatial

802 gradients, which were attributed to ineffective diffusion of the enzyme to the substrate. Since

803 liquefaction occurs nearly six times faster for the mixed samples, it is not surprising that higher

804 final glucose concentrations are also obtained as compared to the unmixed samples and in much

805 less time. For example, the mixed suspension reached $\sim 75 \mathrm{~g} / \mathrm{L}$ glucose in only $\sim 120 \mathrm{hrs,}$

806 whereas the unmixed suspension produced only $\sim 50 \mathrm{~g} / \mathrm{L}$ in $300 \mathrm{hrs}$. Furthermore, adequate

807 initial mixing of the enzyme and substrate resulted in an initial rate of hydrolysis an order of

808 magnitude higher $(1.8 \mathrm{~g} / \mathrm{L} / \mathrm{hr}$ as compared to $0.21 \mathrm{~g} / \mathrm{L} / \mathrm{hr})$. 


\section{Reactor Design for Enzymatic Hydrolysis at High Solids}

Several groups studying the use of high-solids loadings for enzymatic hydrolysis have

812 embraced a horizontal orientation of the reactor $[6,29,62,63]$. Gravitational or free-fall mixing

813 provides many advantages over typical vertical stirred tank reactors and are used in other

814 industrial processes that require mixing highly viscous slurries, like peanut butter, ketchup and

815 concrete $[62,63]$. The horizontal orientation minimizes particle settling and local accumulation

816 of reaction products within the reactor, as well as ensuring better enzyme distribution. These

817 types of reactors are also easily scalable from bench-scale to pilot-scale and larger. Power

818 requirements are lower for horizontal reactors equipped with paddles over vertical stirred tank

819 reactors that provide the same level of effective mixing [62].

820 Roche et al. [63] employed free-fall mixing in their design for bench-scale reactors for

821 enzymatic hydrolysis. Polypropylene bottles $(125 \mathrm{~mL}$ and $250 \mathrm{~mL})$ were placed on a roller

822 apparatus in a horizontal orientation. The roller apparatus and bottles were placed in an

823 incubator for temperature control during enzymatic hydrolysis. This roller-bottle system

824 produced results comparable to shake flasks when utilizing intermittent hand mixing, especially

825 following enzyme addition and prior to sampling, for up to $30 \%$ solids (data not shown). At

$82620 \%$ solids loading, these two mixing schemes resulted in $80-85 \%$ cellulose conversion. The

827 roller-bottle reactors eliminated the human component of mixing, resulting in more consistent

828 mixing and better enzyme and reaction product distribution.

829 Hydrolysis studies conducted by Dasari et al. [62] utilized a horizontal reactor of

830 intermediate capacity $(8 \mathrm{~L})$. The reactor was constructed from a cylinder made of Pyrex glass

831 with aluminum lids fitted over the ends. An adjustable speed, rotating shaft with rubber-tipped,

832 stainless steel blades attached was inserted into the reactor. Three sampling ports were located 
833 along the length of the reactor. Hydrolysis studies comparing the horizontal reactor to shake

834 flasks found, at 25\% solids loading, approximately $10 \%$ more glucose was produced in the

835 horizontal reactor.

836 Jorgensen et al. [29] developed a reactor for use in pretreatment and enzymatic hydrolysis

837 processes with a total volume of $280 \mathrm{~L}$. Several features have been implemented into the pilot-

838 scale drum reactor, as well as the smaller glass reactor, to address issues associated with high-

839 solids loadings. The horizontal orientation of the reactors takes advantage of free-fall mixing,

840 eliminating the need for mechanical mixing. Evaluation of a range of mixing speeds (3.3-11.5

$841 \mathrm{rpm}$ ) by Jorgensen et al. [29] resulted in no significant differences in cellulose conversion over

842 the tested range, so energy input for mixing is significantly reduced as compared to vertically

843 oriented stirred tank reactors. In addition to free-fall mixing, a rotating shaft affixed with

844 paddles supplies additional mixing capabilities, as the shaft in the pilot-scale reactor can be

845 programmed to change rotational direction two times per minute. The paddles also provide a

846 scraping action that removes lignocellulosic material from the reactor walls, improving heat

847 transfer between the reactor and the biomass.

848 The Integrated Biomass Utilization System (IBUS) Project coordinated by DONG

849 Energy in Denmark also utilizes free-fall reactors. DONG Energy has free-fall reactors in a

850 variety of sizes for research and development purposes (400 L) and has successfully scaled one

851 up to a capacity of $11,000 \mathrm{~L}[6,64]$. These reactors routinely operate at approximately $40 \%$

852 solids loading. Larger particle sizes can be used, since the mechanical work of the mixing helps

853 tear biomass fibers and particles apart [6]. This tearing action also increases the surface area of

854 the lignocellulose, resulting in increased enzyme accessibility to the cellulose and hemicellulose. 
While most reactors implemented for high-solids enzymatic hydrolysis have employed

856 some form of free-fall mixing, Zhang et al. [18] investigated the effects of a helical impeller in a

857 vertical reactor on SSF at solids loadings up to $30 \%(\mathrm{w} / \mathrm{w})$ and compared it to a typical Rushton

858 (paddle) impeller (Figure 4a-b). Helical impellers are suggested for use in highly viscous, non-

859 Newtonian fluid agitation, which describes high-solids biomass slurries. The helical impeller

860 performed better than the Rushton impeller with regard to every aspect tested. The feeding rate

861 of lignocellulose into the reactor was adjusted so that a liquefied slurry could be maintained

862 throughout the feeding period. The helical impeller provided better mixing, as the feeding period

863 was completed more than $2 \mathrm{hr}$ sooner than that of the Rushton impeller. The helical impeller also

864 resulted in higher ethanol concentration $(51.0 \mathrm{~g} / \mathrm{L}$ vs. $43.9 \mathrm{~g} / \mathrm{L})$ and productivity, as well as

865 consuming less power. At $30 \%$ solids (prior to inoculation with the fermentative organism), the

866 Rushton impeller required nearly $40 \mathrm{~W} / \mathrm{kg}$ corn stover (CS) before decreasing to 29 W/kg CS

867 after $72 \mathrm{hr}$ of saccharification and fermentation. The helical impeller required $\sim 8 \mathrm{~W} / \mathrm{kg}$ CS and

$868 \sim 1 \mathrm{~W} / \mathrm{kg}$ CS prior to inoculation and after $72 \mathrm{hr}$, respectively. (It should be noted that the

869 stirring rates for the two impellers were different; however, the power requirements were

870 normalized based on the "no-load" power consumption for each impeller.) Lastly, the mixing

871 efficiency of the helical impeller was superior to the Rushton impeller. The geometry of the

872 impeller can play a significant role in effectively mixing biomass slurries. Other geometries

873 tested by Wang et al. include a plate-and-frame impeller and a double-curved-blade impeller

874 (Figure 4c-d). The impellers were tested at various speeds and $100 \mathrm{rpm}$ resulted in the best

875 conversion efficiencies for both geometries. However, the plate-and-frame impeller achieved a

876 higher conversion than the double-curved-blade impeller by nearly $18 \%$, indicating that the

877 geometry of the impeller can have an effect on the hydrolysis. The authors suggested that the 
878 plate-and-frame impeller provides a more consistent mixing regime at every depth in the reactor,

879 whereas the axial flow induced by the double-curved-blade impeller is a function of the distance

880 from the blades.

881 Another study investigated the use of a peg mixer (Figure 4e) for enzymatic hydrolysis at 882 high-solids loadings [43]. The mixer used in this study was a $9 \mathrm{~L}$ reactor fitted with a rotating 883 shaft with pegs extending out radially. The time for liquefaction of $20 \%(\mathrm{w} / \mathrm{w})$ of unbleached 884 hardwood pulp was significantly reduced when comparing shake flasks to the peg mixer ( $40 \mathrm{hr}$ 885 vs. $1 \mathrm{hr}$ ). The benefit of this mixer is that it has been proven effective with lignocellulosic 886 material. High-solids enzymatic hydrolysis is just another application for the peg mixer. From the various aforementioned reactors utilized with high-solids enzymatic hydrolysis 888 reactions, there are several suggestions to improve the mixing of highly viscous slurries. Free889 fall mixing relies on gravity to effectively mix the slurry, which consumes less energy than a 890 stirred tank reactor providing a similar degree of mixing. An effective mixing regime can greatly 891 depend on the impeller geometry, as the shape of an impeller can cause large differences in 892 speed and shear effects at various impeller-slurry interfaces throughout the reactor. High shear 893 rates have been shown to disrupt the adsorption of cellulase onto biomass or to even cause the 894 denaturation of cellulase [65, 66]. Lastly, technology should be borrowed from other 895 applications, where possible. For instance, peg mixers are a "tried-and-true" technology that is 896 commonly used in the long-established pulp and paper industry. All of these ideas have shown 897 some promise but require more study and fine-tuning before being implemented into the 898 lignocellulose conversion process. 


\section{Pilot and Demonstration-Scale Operations}

Several plants operating at pilot- and demonstration -scale level have recently come

902 online. These installations will help the industry gain valuable insights and improve upon the

903 challenges and limitations that are not recognized at the laboratory scale.

904 One such pilot plant constructed in Denmark is operated by Inbicon (a subsidiary of

905 DONG Energy), with a distillation capacity of $\sim 1$ ton fermentation broth/hr. Additionally, in

906 2010, Inbicon opened its demonstration-scale plant that is capable of producing 5.3 million liters

907 of ethanol each year. Enzymatic hydrolysis is performed here at $25-30 \%$ (w/w) solids content

908 with a relatively low enzyme loading of 3-6 FPU/g DM. However, the plant is capable of

909 handling up to $40 \%(\mathrm{w} / \mathrm{w})$ solids in any of its process streams $[6,64]$. Since this operation is

910 also used for developmental purposes, they have reactors that range from $400 \mathrm{~L}$ up to 11,000 L.

911 Additionally, pretreatment and fermentation are performed at high-solids loadings, $20-40 \%$ and

$912 \sim 18 \%$ DM, respectively. At the end of the conversion process, the remaining lignin-rich material

913 (40-95\% DM) is burned to produce heat and electricity that can be cycled back into the

914 conversion operation.

915 The National Renewable Energy Laboratory (Golden, CO, USA) recently expanded their

916 lignocellulose processing facilities to achieve a capacity of 4,000 L and to operate at solids

917 loading of $\geq 20 \%(\mathrm{w} / \mathrm{w})$ [67]. The conversion process is designed as a semi-continuous operation

918 with pretreatment occurring in horizontal reactors with paddles, taking advantage of the reduced

919 energy inputs required with free-fall mixing of lignocellulose. Following liquefaction at $24-30$

$920 \mathrm{hrs}$, the slurry is pumped into vertical, stirred tank reactors to complete the enzymatic hydrolysis

921 of the material. This operation is capable of processing about 0.5 to 1 ton dry biomass into

922 ethanol each day. 


\section{7. Direction of future work}

925 In order to fully realize the benefits of operating enzymatic hydrolysis at high-solids,

926 several issues must be addressed. There are many variables associated with enzymatic

927 hydrolysis that can affect the efficiency of the conversion, including (but not limited to) biomass

928 source, pretreatment method, enzyme source and enzyme mixture. Each of these components

929 must be considered when designing a process for lignocellulose conversion, which makes

930 optimal processing conditions difficult to devise. Further study for the optimization of glucose

931 yields, especially in regards to the use of fed-batch systems, enzyme supplementation, washing

932 and detoxification steps, and additives, both individually and in combination, is still very much

933 needed. It is also important that a better understanding of some of the mechanisms that seem to

934 have the greatest impacts on the conversion process is achieved. Robust reactors capable of

935 effectively mixing biomass slurries to minimize end-product inhibition and heat and mass

936 transfer limitations are needed. Additionally, the cost of enzymes, biomass and any necessary

937 specialty equipment, as well as the best uses for any potential by-products produced in the

938 conversion process, should be considered in the design stages.

$940 \quad$ 8. Conclusions

941 Recent national and international focus on producing biofuels and chemicals from

942 lignocellulose has led to significant research on the development and optimization of effective

943 conversion processes. Several definitive conclusions regarding enzymatic hydrolysis performed

944 at high-solids loadings can be made following a thorough review of the available literature on

945 this topic: 
947 - Free-fall mixing is effective. The advantages of this type of mixing system are

948 numerous, and it has been employed successfully in other industrial processes.

949 - The solids effect is real. Although, the exact cause of this phenomenon has not been

950 determined, there are several hypotheses that have been suggested, including

$951 \quad \circ$ lower cellulase adsorption (increased concentrations of glucose and cellobiose

952 have been shown to inhibit the adsorption of enzymes onto cellulose);

$953 \quad \circ$ product inhibition of enzymes occurs earlier because of the higher concentration

$954 \quad$ of products;

$955 \quad$ inadequate mixing, which can emphasize diffusional limitations exacerbating

$956 \quad$ product inhibition and access of enzyme to substrate;

$957 \quad 0$ interaction of water with substrate (water has been shown to be more tightly

958 bound to lignocellulose as the solids loadings increase, thus less water is

959 available to the enzymes to perform the hydrolysis reaction).

960 - Contradictory evidence continues to raise questions regarding the lignocellulose

961 conversion process. For example, some studies have shown that washing solids

962 following pretreatment can enhance sugar production and fermentation, while others

963 have found the opposite to be true. Additionally, arguments persist regarding the effects

964 water has on the overall conversion process. Lastly, as long as enzyme cost remains a

965 large portion of the overall conversion cost, enzymes also demand further attention,

966 especially with regards to proper loadings and combinations. 
- Fed-batch systems are worth investigating. While there have been some conflicting results, many studies show overwhelming support for conducting high-solids operations as a fed-batch system.

- The use of additives to reduce slurry viscosity has achieved some success at the labscale. However, the economics of the use of additives on an industrial-scale should be validated prior to implementation at that level.

974 lignocellulose more economical and more price-competitive with petroleum. Increasing sugar

975 and ethanol yields while reducing capital and production costs, lowering energy demands and

976 lowering water requirements will contribute to a more economically feasible process as

977 compared to one operated at low- or moderate-solids loadings. Despite all the benefits of

978 operating at high solids, the process remains restricted due primarily to the lack of available

979 water within the culture, high viscosities, which translate to difficulties with mixing and

980 handling, and increased concentration of inhibitors, which extends reaction times and increases

981 enzyme costs. Researchers are attacking these issues from many angles, experimenting with

982 different pretreatment methods and various enzyme sources and cocktails, while modifying

983 operating conditions and slurry properties. Although there has been some success at performing

984 enzymatic hydrolysis at high solids at the pilot and demonstration scale, many questions must be 985 resolved before the full potential of high-solids lignocellulose conversion will be realized.

\section{Acknowledgments}

988 The authors gratefully acknowledge the financial support of the United States

989 Department of Agriculture National Institute for Food and Agriculture, Biomass Research and 
990 Development Initiative Grants \#11000000836 and \#2011-10006-30363. The investigation 991 reported in this study (No. 12-05-116) is a part of a project of the Kentucky Agricultural 992 Experiment Station and is published with the approval of the director. 


\section{References}

994 [1] Hodge DB, Karim MN, Schell DJ, McMillan JD. Model-based fed-batch for high-solids 995 enzymatic cellulose hydrolysis. Applied Biochemistry and Biotechnology 2009;152:88.

996 [2] Hodge DB, Karim MN, Schell DJ, McMillan JD. Soluble and insoluble solids

997 contributions to high-solids enzymatic hydrolysis of lignocellulose. Bioresour Technol

$998 \quad 2008 ; 99: 8940$.

999 [3] Roche CM, Dibble CJ, Knutsen JS, Stickel JJ, Liberatore MW. Particle concentration and

1000 yield stress of biomass slurries during enzymatic hydrolysis at high-solids loadings. Biotechnol

1001 Bioeng 2009;104:290.

1002 [4] Humbird D, Mohagheghi A, Dowe N, Schell DJ. Economic impact of total solids loading 1003 on enzymatic hydrolysis of dilute acid pretreated corn stover. Biotechnology Progress

$10042010 ; 26: 1245$.

1005 [5] Kristensen JB, Felby C, Jorgensen H. Determining yields in high solids enzymatic

1006 hydrolysis of biomass. Applied Biochemistry and Biotechnology 2009;156:557.

1007 [6] Larsen J, Petersen MO, Thirup L, Li HW, Iversen FK. The IBUS process -

1008 Lignocellulosic bioethanol close to a commercial reality. Chemical Engineering \& Technology

$1009 \quad 2008 ; 31: 765$.

1010 [7] Banerjee S, Mudliar S, Sen R, Giri B, Satpute D, Chakrabarti T, et al. Commercializing 1011 lignocellulosic bioethanol: Technology bottlenecks and possible remedies. Biofuels Bioproducts

1012 \& Biorefining-Biofpr 2010;4:77.

1013 [8] Um BH, Hanley TR. A comparison of simple rheological parameters and simulation data

1014 for Zymomonas mobilis fermentation broths with high substrate loading in a 3-L bioreactor.

1015 Applied Biochemistry and Biotechnology 2008;145:29. 
1016 [9] Modenbach AA, Nokes SE. The use of high-solids loadings in biomass pretreatment - A 1017 review. Biotechnol Bioeng 2012;109:1430.

1018 [10] Kristensen JB, Felby C, Jorgensen H. Yield-determining factors in high-solids enzymatic 1019 hydrolysis of lignocellulose. Biotechnology for Biofuels 2009;2.

1020 [11] Gervais P, Bensoussan M, Grajek W. Water activity and water content - Comparative 1021 effects on the growth of Penicillium roqueforti on solid substrate. Applied Microbiology and 1022 Biotechnology 1988;27:389.

1023 [12] Gruno M, Valjamae P, Pettersson G, Johansson G. Inhibition of the Trichoderma reesei 1024 cellulases by cellobiose is strongly dependent on the nature of the substrate. Biotechnol Bioeng $1025 \quad 2004 ; 86: 503$.

1026 [13] Holtzapple M, Cognata M, Shu Y, Hendrickson C. Inhibition of Trichoderma reesei 1027 cellulase by sugars and solvents. Biotechnol Bioeng 1990;36:275.

1028 [14] Kim Y, Ximenes E, Mosier NS, Ladisch MR. Soluble inhibitors/deactivators of cellulase 1029 enzymes from lignocellulosic biomass. Enzyme and Microbial Technology 2011;48:408.

1030 [15] Qing Q, Yang B, Wyman CE. Xylooligomers are strong inhibitors of cellulose hydrolysis 1031 by enzymes. Bioresour Technol 2010;101:9624.

1032 [16] Ximenes E, Kim Y, Mosier N, Dien B, Ladisch M. Inhibition of cellulases by phenols. 1033 Enzyme and Microbial Technology 2011;46:170.

1034 [17] Gupta R, Lee YY. Mechanism of cellulase reaction on pure cellulosic substrates.

1035 Biotechnol Bioeng 2009;102:1570.

1036 [18] Zhang J, Chu DQ, Huang J, Yu ZC, Dai GC, Bao J. Simultaneous saccharification and 1037 ethanol fermentation at high corn stover solids loading in a helical stirring bioreactor. Biotechnol 1038 Bioeng 2010;105:718. 
1039 [19] Xu F, Ding HS. A new kinetic model for heterogeneous (or spatially confined) enzymatic 1040 catalysis: Contributions from the fractal and jamming (overcrowding) effects. Applied Catalysis 1041 a-General 2007;317:70.

1042 [20] Bommarius AS, Katona A, Cheben SE, Patel AS, Ragauskas AJ, Knudson K, et al. 1043 Cellulase kinetics as a function of cellulose pretreatment. Metabolic Engineering 2008;10:370.

1044 [21] Ehrhardt MR, Monz TO, Root TW, Connelly RK, Scott CT, Klingenberg DJ. Rheology 1045 of dilute acid hydrolyzed corn stover at high solids concentration. Applied Biochemistry and 1046 Biotechnology 2010;160:1102.

1047 [22] Knutsen JS, Liberatore MW. Rheology of high-solids biomass slurries for biorefinery 1048 applications. Journal of Rheology 2009;53:877.

1049 [23] Stickel JJ, Knutsen JS, Liberatore MW, Luu W, Bousfield DW, Klingenberg DJ, et al. 1050 Rheology measurements of a biomass slurry: An inter-laboratory study. Rheologica Acta $10512009 ; 48: 1005$.

1052 [24] Viamajala S, McMillan JD, Schell DJ, Elander RT. Rheology of corn stover slurries at 1053 high solids concentrations - Effects of saccharification and particle size. Bioresour Technol $10542009 ; 100: 925$.

1055 [25] Samaniuk JR, Scott CT, Root TW, Klingenberg DJ. Rheological modification of corn 1056 stover biomass at high solids concentrations. Journal of Rheology 2012;56:649.

1057 [26] Rosgaard L, Andric P, Dam-Johansen K, Pedersen S, Meyer AS. Effects of substrate 1058 loading on enzymatic hydrolysis and viscosity of pretreated barley straw. Applied Biochemistry 1059 and Biotechnology 2007;143:27. 
1060 [27] Dibble CJ, Shatova TA, Jorgenson JL, Stickel JJ. Particle morphology characterization 1061 and manipulation in biomass slurries and the effect on rheological properties and enzymatic 1062 conversion. Biotechnology Progress 2011;27:1751.

1063 [28] Zhu JY, Gleisner R, Scott C, Luo XL, Tian S. High titer ethanol production from 1064 simultaneous enzymatic saccharification and fermentation of aspen at high solids: A comparison 1065 between SPORL and dilute acid pretreatments. Bioresour Technol 2011;102:8921.

1066 [29] Jorgensen H, Vibe-Pedersen J, Larsen J, Felby C. Liquefaction of lignocellulose at high1067 solids concentrations. Biotechnol Bioeng 2007;96:862.

1068 [30] Szijarto N, Siika-aho M, Sontag-Strohm T, Viikari L. Liquefaction of hydrothermally 1069 pretreated wheat straw at high-solids content by purified Trichoderma enzymes. Bioresour 1070 Technol 2011;102:1968.

1071 [31] Knutsen JS, Liberatore MW. Rheology modification and enzyme kinetics of high solids 1072 cellulosic slurries. Energy \& Fuels 2010;24:3267.

1073 [32] Brown L, Torget R. Enzymatic saccharificiation of lignocellulosic biomass. Golden, CO:

1074 National Renewable Energy Laboratory; 1996.

1075 [33] Zhang YHP, Schell DJ, McMillan JD. Methodological analysis for determination of 1076 enzymatic digestibility of cellulosic materials. Biotechnol Bioeng 2007;96:188.

1077 [34] Zhu YM, Malten M, Torry-Smith M, McMillan JD, Stickel JJ. Calculating sugar yields in 1078 high solids hydrolysis of biomass. Bioresour Technol 2011;102:2897.

1079 [35] Lau MW, Dale BE, Balan V. Ethanolic fermentation of hydrolysates from ammonia fiber 1080 expansion (AFEX) treated corn stover and distillers grain without detoxification and external 1081 nutrient supplementation. Biotechnol Bioeng 2008;99:529. 
1082 [36] Pristavka A, Kodituvakky PA, Kozlov YP, Zacchi G, Berezin IV, Rabinovich ML. High1083 solids enzymatic hydrolysis of steam-exploded willow without prior water washing. Applied 1084 Biochemistry and Microbiology 2000;36:101.

1085 [37] Lu YF, Wang YH, Xu GQ, Chu J, Zhuang YP, Zhang SL. Influence of high solid 1086 concentration on enzymatic hydrolysis and fermentation of steam-exploded corn stover biomass. 1087 Applied Biochemistry and Biotechnology 2010;160:360.

1088 [38] Lau MW, Dale BE. Cellulosic ethanol production from AFEX-treated corn stover using 1089 Saccharomyces cerevisiae 424A(LNH-ST). Proceedings of the National Academy of Sciences of 1090 the United States of America 2009;106:1368.

1091 [39] Wang W, Zhuang XS, Yuan ZH, Yu Q, Qi W, Wang Q, et al. High consistency 1092 enzymatic saccharification of sweet sorghum bagasse pretreated with liquid hot water. Bioresour 1093 Technol 2012;108:252.

1094 [40] Schwald W, Breuil C, Brownell HH, Chan M, Saddler JN. Assessment of pretreatment 1095 conditions to obtain fast complete hydrolysis on high substrate concentrations. Applied 1096 Biochemistry and Biotechnology 1989;20-1:29.

1097 [41] Cara C, Moya M, Ballesteros I, Negro MJ, Gonzalez A, Ruiz E. Influence of solid 1098 loading on enzymatic hydrolysis of steam exploded or liquid hot water pretreated olive tree 1099 biomass. Process Biochemistry 2007;42:1003.

1100 [42] Xue Y, Jameel H, Phillips R, Chang HM. Split addition of enzymes in enzymatic 1101 hydrolysis at high solids concentration to increase sugar concentration for bioethanol production. 1102 Journal of Industrial and Engineering Chemistry 2012;18:707.

1103 [43] Zhang X, Qin WJ, Paice MG, Saddler JN. High consistency enzymatic hydrolysis of 1104 hardwood substrates. Bioresour Technol 2009;100:5890. 
1105 [44] Di Risio S, Hu CS, Saville BA, Liao D, Lortie J. Large-scale, high-solids enzymatic 1106 hydrolysis of steam-exploded poplar. Biofuels Bioproducts \& Biorefining-Biofpr 2011;5:609.

1107 [45] Chandra RP, Au-Yeung K, Chanis C, Roos AA, Mabee W, Chung PA, et al. The 1108 influence of pretreatment and enzyme loading on the effectiveness of batch and fed-batch 1109 hydrolysis of corn stover. Biotechnology Progress 2011;27:77.

1110 [46] Yang J, Zhang XP, Yong QA, Yu SY. Three-stage enzymatic hydrolysis of steam1111 exploded corn stover at high substrate concentration. Bioresour Technol 2011;102:4905.

1112 [47] Zambare VP, Bhalla A, Muthukumarappan K, Sani RK, Christopher LP. Bioprocessing 1113 of agricultural residues to ethanol utilizing a cellulolytic extremophile. Extremophiles $1114 \quad 2011 ; 15: 611$.

1115 [48] Lau MW, Gunawan C, Balan V, Dale BE. Comparing the fermentation performance of 1116 Escherichia coli KO11, Saccharomyces cerevisiae 424A(LNH-ST) and Zymomonas mobilis 1117 AX101 for cellulosic ethanol production. Biotechnology for Biofuels 2010;3.

1118 [49] Dien BS, Ximenes EA, O'Bryan PJ, Moniruzzaman M, Li XL, Balan V, et al. Enzyme 1119 characterization for hydrolysis of AFEX and liquid hot-water pretreated distillers' grains and 1120 their conversion to ethanol. Bioresour Technol 2008;99:5216.

1121 [50] Garcia-Aparicio MP, Oliva JM, Manzanares P, Ballesteros M, Ballesteros I, Gonzalez A, 1122 et al. Second-generation ethanol production from steam exploded barley straw by Kluyveromyces 1123 marxianus CECT 10875. Fuel 2011;90:1624.

1124 [51] Jorgensen H. Effect of nutrients on fermentation of pretreated wheat straw at very high 1125 dry matter content by Saccharomyces cerevisiae. Applied Biochemistry and Biotechnology $1126 \quad 2009 ; 153: 44$. 
1127 [52] Zhang Y, Liu YY, Xu JL, Yuan ZH, Qi W, Zhuang XS, et al. High solid and low enzyme

1128 loading based saccharification of agriculutural biomass. BioResources 2012;7:345.

1129 [53] Ingram T, Wormeyer K, Lima JCI, Bockemuhl V, Antranikian G, Brunner G, et al.

1130 Comparison of different pretreatment methods for lignocellulosic materials. Part I: Conversion of

1131 rye straw to valuable products. Bioresour Technol 2011;102:5221.

1132 [54] Quiroga AG, Costa A, Filho RM. Analysis of conversion and operation strategies for 1133 enzymatic hydrolysis of lignocellulosic biomass in a series of CSTRs with distributed feeding.

1134 Bioprocess and Biosystems Engineering 2010;33:901.

1135 [55] Ma XX, Yue GJ, Yu JL, Zhang X, Tan TW. Enzymatic Hydrolysis of Cassava Bagasse

1136 with High Solid Loading. Journal of Biobased Materials and Bioenergy 2011;5:275.

1137 [56] Roberts KM, Lavenson DM, Tozzi EJ, McCarthy MJ, Jeoh T. The effects of water 1138 interactions in cellulose suspensions on mass transfer and saccharification efficiency at high 1139 solids loadings. Cellulose 2011;18:759.

1140 [57] Lavenson DM, Tozzi EJ, Karuna N, Jeoh T, Powell RL, McCarthy MJ. The effect of 1141 mixing on the liquefaction and saccharification of cellulosic fibers. Bioresour Technol $1142 \quad 2012 ; 111: 240$.

1143 [58] Olsen SN, Lumby E, McFarland K, Borch K, Westh P. Kinetics of enzymatic high-solid 1144 hydrolysis of lignocellulosic biomass studied by calorimetry. Applied Biochemistry and 1145 Biotechnology 2011;163:626.

1146 [59] U.S. Department of Energy Office of the Biomass Program. Multi-Year Program Plan. 1147 Washington, DC; 2011. 
1148 [60] Matano Y, Hasunuma T, Kondo A. Display of cellulases on the cell surface of

1149 Saccharomyces cerevisiae for high yield ethanol production from high-solid lignocellulosic

1150 biomass. Bioresour Technol 2012;108:128.

1151 [61] Szijarto N, Horan E, Zhang JH, Puranen T, Siika-aho M, Viikari L. Thermostable

1152 endoglucanases in the liquefaction of hydrothermally pretreated wheat straw. Biotechnology for

1153 Biofuels 2011;4.

1154 [62] Dasari RK, Dunaway K, Berson RE. A scraped surface bioreactor for enzymatic

1155 saccharification of pretreated corn stover slurries. Energy \& Fuels 2009;23:492.

1156 [63] Roche CM, Dibble CJ, Stickel JJ. Laboratory-scale method for enzymatic

1157 saccharification of lignocellulosic biomass at high-solids loadings. Biotechnology for Biofuels

$1158 \quad 2009 ; 2$.

1159 [64] Jorgensen H, Kristensen JB, Felby C. Enzymatic conversion of lignocellulose into

1160 fermentable sugars: Challenges and opportunities. Biofuels Bioproducts \& Biorefining-Biofpr $1161 \quad 2007 ; 1: 119$.

1162 [65] Cao Y, Tan HM. The effect of shear field on the hydrolysis of cellulose. Journal of 1163 Macromolecular Science-Physics 2004;B43:1115.

1164 [66] Kaya F, Heitmann JA, Joyce TW. Deactivation of cellulase and hemicellulase in high 1165 shear fields. Cellulose Chemistry and Technology 1996;30:49.

1166 [67] National Renewable Energy Laboratory. Biomass Research. 